\title{
Die Staarausziehung bei den Griechen und Römern.
}

Vorläufige Mittheilung aus meiner demnächst erscheinenden Geschichte des grauen Staars.

\section{Von}

Dr. Hugo Magnus,

Privatdocent der Augenheilkunde an der Universität Breslau.

\section{Abschnitt.}

Ueber die Existenz und die Natur der antiken Staarausziehung.

Die Frage nach der Existenz einer Extractionsmethode des Staars bei den Griechen und Römern ist, trotzdem sie bereits von den verschiedensten Autoren eine eingehende kritische Beleuchtung wiederholentlich erfahren hat, doch noch als eine ungelöste und offene anzusehen. Denn während die Einen nicht abgeneigt sind, gestützt auf die Autorität des Plinius, bereits der vorchristlichen Zeit die Kenntniss dieser Operationsmethode zuzuerkennen, suchen die Andern die ersten Anfänge der Extraction erst im 3. und 4. Jahrhundert der christlichen Zeitrechnung; und so bemerken wir denn, dass anch heute noch der Ausspruch des unvergesslichen Graefe (18):*) „Gewiss bleibt die Wiegenperiode der

*) Separat-Abdruck p. 6. 
Fxtraction eins der schwierigsten Capitel der Geschichtsforschung" in seiner ganzen verhängnissvollen Tragweite sich erhalten hat und dass, trotzdem die gewiegtesten Kenner der Geschichte der Medicin in neuerer Zeit Licht und Aufklärung in diesen dunklen, viel umstrittenen Theil unserer Wissenschaft $z u$ bringen bemüht gewesen sind, doch der Schleier, welcher die Zustände der antiken Extractionsmethode dicht umfangen hält, nur erst wenig gelüftet ist. Meine, schon seit längerer Zeit ausschliesslich auf die Geschichte des grauen Staares und seiner Behandlungsmethoden gerichteten historischen Studien haben mich nun, so hoffe ich, in den Stand gesetzt, zur Lösung dieser Frage einen, vielleicht nicht ganz unwesentlichen Beitrag liefern zu können.

Um eine sichere und verlässliche Basis für den Aufbau unserer Schlüsse und Folgerungen zu gewinnen, werden wir natürlich in erster Linie die verschiedenen Stellen aus den Werken der Alten, welche direct von einer Ausziehung des Staars sprechen, oder von neueren Autoren mit derselben in Verbindung gebracht worden sind, einer nochmaligen kritischen Prüfung unterwerfen müssen.

Als erste und älteste Erwähnung der Ausziehung des grauen Staares wird von einzelnen Autoren die gerade in letzter Zeit so oft genannte Stelle aus dem XXIX. Buch des Plinius angezogen. Diese Stelle (37)*) lautet: „Ne avaritiam quidem arguam rapacisque nundinas pendentibus fatis et dolorum indicaturam ac mortis arram aut arcana praecepta, squamam in oculis emovendam potius quam extrahendam, per quae effectum est ut nihil magis pro re videretur quam multitudo grassantium." Von den älteren Commentatoren des Plinius scheint diese Stelle fast immer mit der Operation des

*) Band 4, p. 340 . 
grauen Staares in Zusammenhang gebracht worden $z u$ sein. So lesen wir in der von Dalecamp (35)*) besorgten Ausgabe des Plinius als Erklärung zu dem Wort emovendam „deorsum pellendum acu", ein Ausdruck, der offenbar nur auf die Depression des Staares hinzielen soll. Der gleichen Auffassung begegnen wir bei Hardu in (36)**); er erklärt den Ausdruck squamam in oculis emovendam durch folgenden Zusatz: ,deorsum pellendam acu, unde subire sursum possit adhuc et medici operam iterum flagitare." Hier haben wir also einen ganz zweifellosen Hinweis auf die Depression des Staares und die in dieser Operationsmethode liegende Gefahr eines abermaligen Aufsteigens der niedergedrückten Linse. In der neueren Zeit war es ganz besonders Hasner (24 und 25)*), der diese kurze Notiz als sicheren Beweis der Existenz der Extractionsmethode in der vorchristlichen Zeit hinstellte, und in ihr bereits die Spuren des erbitterten Kampfes zwischen Depression und Extraction zu erblicken glaubte, der erst achtzehn Jahrhunderte spăter die oculistische Welt erschüttern sollte. Auf das Missliche und Willkührliche, welches in der Uebersetzung und Deutung, die Hasner der in Rede stehenden Stelle glebt, liegt, haben bereits v. Gräfe (18)*) und Hirsch (27)**) aufmerksam gemacht. Hirsch hebt mit vollstem Recht hervor, dass von keinem medicinischen Schriftsteller des römischen Alterthums das Wort squama für Staar gebraucht werde, sondern sich dieselben stets des Wortes suffusio bedient haben. Ich muss dieser Bemerkung von Hirsch durchaus beistimmen; bei allen Autoren jener Epoche, die ich einzusehen Gelegenheit

*) Band 2, p. 1281.

**, Band 8. p. 357.

***) p. 3 und Cap II, p. 6-12.

t) p. 3 u. 4 .

††) p. $282-292$. 
gehabt habe, habe ich nur den Ausdruck suffusio für Staar gefunden. Besonders auffallend ist es mir aber gewesen, dass Plinius, obschon er an den verschicdensten Stellen seiner Historia naturalis vom grauen Staar, seiner Natur und seiner Behandlung spricht, sich doch niemals des Wortes "squama" bedient, vielmehr stets nur "suffusio" gebraucht. Und man sollte doch wohl glauben, dass, wenn überhaupt Plinius squama und suffusio identificirt hätte, er nicht mit der grössten Beharrlichkeit in allen Büchern seines Werkes nur suffusio gebraucht, vielmehr gelegentlich mit beiden Worten abgewechselt haben würde. Das hat er aber bestimmt nicht gethan, vielmehr überall da, wo er in klarer und zweifelloser Weise vom granen Staar spricht, ausschliesslich das Wort suffusio in Anwendung gezogen. Wenn wir nun schon im Hinblick auf diesen Umstand uns eines gewissen Zweifels an der von Hasner postulirten Identität von squama und suffusio nicht entschlagen können, so erstarkt dieser Zweifel geradezu zur Ungläubigkeit, wenn wir bemerken, dass sowohl squama, als wie auch das analoge $\lambda \varepsilon \pi i \zeta$, resp. $\lambda \varepsilon \pi i \zeta \omega$, wiederholentlich von Augenerkrankungen, die bestimmt nicht cataractöser Natur waren, gebraucht wurden.

So gebraucht z. B. Marcellus (31)*) der Empiriker*) das Wort squama, um gewisse den äusseren Theilen des Augapfels aufsitzende pathologische Gebilde zu bezeichnen. Bei Erwähnung eines Mittels, das bei Leucomen in Anwendung gezogen werden sollte, sagt er über die Wirkungsweise desselben: „Post haec inunge oculum leni collyrio, statim emittet quasi squamam."

Und ganz dem nämlichen Gebrauch von $\lambda \varepsilon \pi i \varsigma$, resp.

*) pag. 68 . 
$\lambda \varepsilon \pi i \zeta \omega$ begegnen wir in der Septuaginta (45)*); Buch Tobit - die Zeit der Abfassung gerade dieses Buches dürfte von der hier in Rede stehenden Zeitepoche des Plinius nicht allzuweit abliegen $\left.(15)^{* *}\right)$ - heisst es:

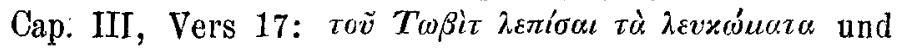

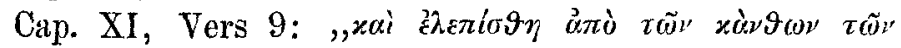

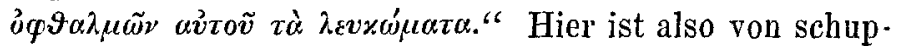
pigen Gebilden in den Augen die Rede; die Leukome der Augen lösten sich in Schuppenform los, schuppten sich ab. Wenn wir nun auch über die Natur der Augenerkrankung des Tobit aus der gesammten Erzählung gewiss kein sonderlich klares Bild $\mathrm{zu}$ gewinnen vermögen, so können wir doch so viel mit Gewissheit behaupten, dass eine cataractöse Veränderung des Auges durch dieselbe nicht geschildert, sich dieselbe vielmehr offenbar nur auf eine in den äusseren Gebilden der Augen, wahrscheinlich der Cornea, localisirte Krankheit beziehen soll. Welcher Art dieselbe schliesslich gewesen, dies zu untersuchen, müssen wir dem Scharfsinn der gelehrten Commentatoren des Buches Tobias (13) überlassen, und wollen uns hier nur damit begnügen, das Factum zu constatiren, dass das dem lateinischen squama analoge $\lambda \varepsilon \pi i c$, resp. $\lambda \varepsilon \pi i \zeta \omega$ gerade an der Stelle, wo es von Erkrankungen der Augen gebraucht wird, nicht auf den grauen Staar, sondern auf eine pathologische Veränderung in den äusseren Gebilden des Bulbus bezogen wird. Ich will übrigens hier noch beiläufig bemerken, dass von einzelnen älteren Autoren das Wort squama als Termi-

*) Tomus primus, pag. 636 und 642 .

**; Ist nach Fritzsche's Vermuthung in seinem Commentar zu den Büchern Tobi und Judith (aus dem kuragefassten exegetischen Handbuch zu den Apokryphen, Leipzig 1853, p. 16, § 10) wahrscheinlich kurz vor oder kurz nach dem Makkabäischen Freiheitskampf geschrieben, also in der Zeit der beiden letzten vorchristlichen Jahrhunderte, genauer zwischen 180 v. Chr. und Christi Geburt selber.

v. Graefe's Archiv für Ophthalmologie, XXII. 2. 
nus technicus für die vier verschiedenen Schichten, welche bereits die alte Oculistik an der Hornhaut unterschied, gebraucht wird. So finden wir im Continens des Rhases $(39)^{*}$ ) die einzelnen Schichten der Hornhaut als squamae bezeichnet. Genau in derselben Weise werden in der lateiuischen Uebersetzung des $\mathrm{Haly} \cdot \mathrm{Ab}$ bas (23)*) die Hornhautschichten squamae genannt. Und begegnen wir in dem Commentar des Gentilis Fulginatis (9)***) zu dem Canon des Avicenna demselben Gebrauch. Uns will es aber dünken, als wenn man im Hinblick auf diese Thatsachen doch viel eher dazu berechtigt sei, in analoger Weise squama auf einen in den äusseren Gebilden des Augapfels, wahrscheinlich der Hornhaut, localisirten pathologischen Process za beziehen, als ihm die Bedeutung "Staar" zu vindiciren, in welcher es nachweislich von keinem einzigen Autor der lateinisch-medicinischen Literatur gebraucht worden ist. Mir scheint deshalb $\mathrm{Has}$ ner bei seiner Uebertragung der angezogenen Stelle des Plinius in ähnlicher Weise sich einer etwas kühnen poetischen Licenz bedient $z u$ haben, wie dies auch Luther gethan hat, wenn er die bewusste Stelle des eilften $\mathrm{Ca}$ pitals im Buch Tobias übersetzt: „Und der Staar ging ihm von den Augen wie ein Häutlein von einem Ei."

Wenn wir also auch nicht geneigt sein können, die in Rede stehende Stelle des Plinius mit der Extraction des grauen Staares in irgend einen Zusammenhang zu bringen, so glauben wir dafür bei anderen Autoren des Alterthums einen um so klareren und zweifelloseren Fin. weis auf ein Operationsverfahren gefunden za haben, vermittelst dessen die Alten Anhäufungen gewiscer patho. logischer Produkte im Auge, die sie dem Begriff Suffusio, Hypochysis, Staar unterstellten, denen aber unsore

*) Lib. II, Cap. II, Fol. 53 a.

**) Pars prima. Lib. IX, Cap, 13, Fol. $106 \mathrm{~b}$.

***) Lib. III, Fen. III, Tractat II, Cap. X. 
moderne Okulistik einen ganz anderen Standpunkt in ihrem pathologischen System anweist, auf dem Wege der Entleerung aus dem Auge zu entfernen suchten, also, wenn wir so wollen, eine Extraction des Staares vornahmen. So finden wir eine derartige Angabe im A elianus (2)*). Indem er nämlich die bekannte Fabel von den Ziegen erzählt, die erblindet zu einem Dornenstrauch gehen, sich das erblindete Auge mit einem Dorn öffnen und so das Gesicht wieder erlangen, sagt er, diese Augenkrankbeit der Ziegen wäre das, was die Aerzte Hypochysis, also Staar nennen und der Erfolg der Oneration mittelst des Dornes wäre der, dass die den Staar bildende Flüssigkeit aus dem Auge austlösse;

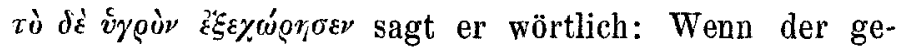
lehrte Triller (46)**) geneigt scheint, diese Fabel eher auf die Scarification des mit Blut unterlaufenen Auges zu beziehen, als auf die Staaroperation, so müssen wir gestehen, dass wir dieser Auffassung, die von dem Text doch allzu sehr abweicht, nicht beizustimmen vermögen, sondern dass wir, uns einfach streng an den Wortlaut haltend, in der Erzäblung des Aelian einen zweifellosen Hinweis auf eine Operationsmethode des Staares erblicken. Um meinen Lesern ein eigenes Urtheil über diese unsere Deutung der in Rede stehenden Stelle zu ermöglichen, möge dieselbe hier angeführt sein; sie lautet:

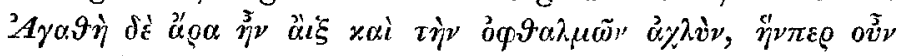

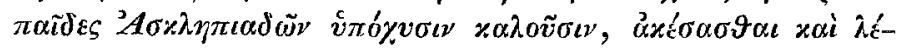

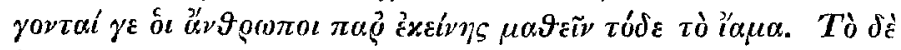

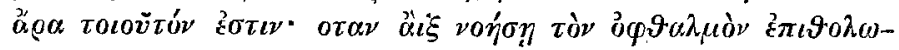

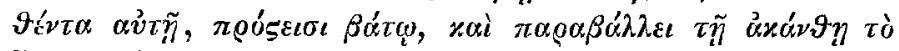

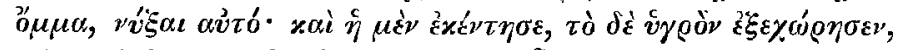

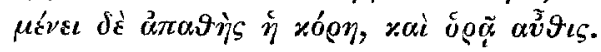

Triller übersetzt diese Stelle folgendermassen:

*) Lib. 7, Cap. 14.

**) p. 8 und 9 . 
„Caliginem oculorum, quam suffusionem vocant Aesculapii filii, caprinum probe curare scit: et ab ipsa capra remedium ejusdem, homines quoque mutuati dicuntur. Quum enim capra conturbatum oculum et non probe affectum ad videndum sentit, ad rubrum accedit, ejusque spinae propius admovet oculum, ut ipse ab ea compungatur: Haec autem ut pupugit, pituita statim effluit, illaesa tamen manente pupilla, ipsaque capra vidend $d_{i}$ usum recuperat."

Sehen wir diese Stelle, ohne jedes Vorurtheil und ohne jede Voreingenommenheit mit streng kritischen Blicken an, so werden wir gestehen müssen, dass in ganz klarer und zweifelloser Weise in ihr von dem Staar gehandelt wird. Wird ja das in Rede stehende Augenleiden geradezu mit dem Wort vлtóxvors bezeichnet, ein Ausdruck, welcher von den griechischen Aerzten als Terminus technicus für Staar benutzt wurde. Sodann spricht auch schon der Umstand, dass Aelian ausdrücklich betont, die Pupille bleibe aber nach der Operation unverletzt, dafür, dass er die Staaroperation bei seiner Erzählung im Sinn gehabt habe und nicht einfach nur die Scarification. Denn bei der Ausübung der Scarification hat ja die Pupille keinerlei Beschädigungen zu befürchten und es wäre somit doch kaum begreiflich, warum Aelian, wollte er auf eine Operation hindeuten, die die Pupille in keiner Weise gefährde, wie dies bei der Scarification der Fall ist, ausdrücklich hervorhebt, die Pupille bleibe aber unverletzt. Uebrigens scheint bei den Alten die Ziege ziemlich allgemein als Erfinderin der Staaroperation gegolten zu haben, so schreibt ihr z. B. Galen (17)*) die Erfindung, staarkranke Augen operativ zu behandeln, zu.

Auffallen muss dagegen in dieser Stelle die Wen-

*) Introductio, Cap. 1. 


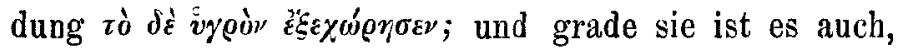
welche für uns ein ganz besonderes Interesse hat und der gesammten Stelle einen absonderlichen Werth verleiht. Denn sie beweist, dass die Alten bereits zur Zeit des Aelian ein operatives Verfahren kannten, vermittelst dessen sie gewisse pathologische Produkte im Auge, die sie als Staar ansprachen, aus dem Bulbus entfernten. Dem Aelian hat offenbar, als er jene Fabel von den Ziegen niederschrieb, diese bei seinen Zeitgenossen übliche Operationsmethode vorgeschwebt und er hat nach ihrem Vorbild den Text seiner Erzählung eingerichtet. Es könnte aber hierbei doch noch den Einen oder den Andern der Umstand befremden, dass A elian den Staar mit vyoò bezeichnet, ihn also als eine flüssige Masse schildert. Doch auch hierfür haben wir eine so treffende Erklärung zur Hand, dass wir glauben dürfen, durch sie die angezogene Stelle auf das Beste erklären zu können. Die Vorstellung, welche die Alten sich von der Natur und dem Wesen des Staares machten, weicht bekanntlich von unserer modernen Anschauung auf das Erheblichste ab. Die Alten, Griechen wie Römer, sahen in dem Staar, wie dies auch die bei ihnen üblichen Be. zeichnungen vंróyvoı und suffusio erkenuen lassen, nichts als den Erguss einer fremden Flüssigkeit in den zwischen Linse und Hornhaut befindlichen Raum. Durch allmähliches Erstarren und Gerinnen bildete sich aus, diesem von Anfang an flüssigen Erguss ein Häutchen, das durch Verschluss der Pupille Blindheit erzeugen sollte. Auf Grund dieser Vorstellung von den pathologischen Verhältnissen des Staares sprachen sie natürlich allerlei Erkrankungen des Auges, bei denen sie plastisch-seröse Ergüsse in der vorderen Kammer beobachteten, als Staar an; stellten also eine ganze Menge von krankhaften Processen, die mit dem Staar absolut nichts zu schaffen haben, dem Begriff Staar unter. So ist es denn ge- 
kommen, dass wir eine ganze Reihe von pathologischen Zuständen des Auges, welche die moderne Okulistik unter dem Sammelnamen Hypopyon vereinigt, in den Werken der Alten als Staar beschrieben finden. Wir wollen übrigens hier gleich, um uns gegen jeden Einwurf zu wahren, bemerken, dass den Griechen, wie den Römern die Ansammlung von Eiter in der vorderen Kammer durchaus nicht etwa eine unbekannte Erscheinung gewesen ist, sie vielmehr dieselbe gekannt und auch sogar operativ behandelt haben; nur war ihre Kenntniss von jenen beiden Zuständen, dem Staar wie dem Hypopyon, nicht eine so klare und geläuterte, um beide unter allen Verhältnissen stets streng zu scheiden. Vielmehr liefen die Vorstellungen, welche sie von beiden hatten, vielfach unter einander zusammen und deckten sich häufig ganz. Man braucht bloss die Differenzialdiagnose zu lesen, welche einzelne ihrer Autoren von Staar und Hypopyon geben, um zu erkennen, wie unklar und verschwommen ihnen die Grenze zwischen beiden Krankheitsbildern war; man sehe z. B. die einschlägige Stelle bei Galen (17)*) an, und man wird meine Behauptung vollkommen bestätigt finden. Und auch in der arabischen, sowie der abendländischen Ophthalmologie des Mittelalters, die sich ja in ihren Hauptzügen wesentlich nur aus den Vorstellungen und Anschauungen der Alten aufgebaut hatten, begegnen wir noch diesem Identificiren von Hypopyon und Staar. So sagt z. B. Albucas is (4)**) über die Ansammlung von Eiter im Aage wie folgt: "Hic morbus qui nominatur Alcomnati, est in oculo collectum pus, quod aquae est similis descendenti, et cum illa confunditur." Gentilis (9)***), ein Commentator des Avicenna, erklärt geradezu die Ansammlung von

*) Method. med. lib. XIV.

**) Tom. I, Lib. II, Sect. XXII, p. 167.

***) Lib. III, Fen. III, Tractat II, Cap. X. 
Eiter hinter der Cornea für eine Art von Staar. Im engsten Anschluss an diese Anschauung des Avicenna nennt Wilhelm von Saliceto (20)*) die Ansammlung von Eiter in der vorderen Kammer Staar. In ähnlicher Weise hat übrigens bereits Malgaigne (5)**) darauf aufmerksam gemacht, dass im Alterthum Suffusio resp. vंóxyoıs und Hypopyon Zustände gewesen seien, die sich nicht durch eine scharf gezogene Grenze gegen einander abgesetzt haben. Bei Gelegenheit der Staarextraction, von der Rhases, Avicenna und Albucasis sprechen, sagt er: "Toutefois je remarquerai que ce procédé n'a probablement été imaginé que pour l'hypopyon, que beaucoup d'auteurs de cette époque ne distinguaient pas bien nettement de la cataracte."

Im Besitz dieser Erkenntniss. wird es nun leicht fallen, jene Stelle des Aelianus zu verstehen. Die von ihm als Staar bezeichnete Flüssigkeit, von deren Ausleerung aus dem Auge er spricht, ist hiernach offenbar nichts wie ein Hypopyon gewesen, und somit die betreffende Operation wohl nach den Begriffen der antiken Ophthalmologie eine Extraction des Staares, nach denen der modernen Okulistik aber nichts als eine Entleerung eines plastisch serösen Ergusses aus der vorderen Kammer. Es ist somit also die operative Entleerung des Hypopyon und die von den Alten als Extraction des Staares beschriebene Operation als identisch anzusehen.

Uebrigens scheinen bereits selbst ältere Autoren, die in ihren ophthalmologischen Kenntnissen noch durchaus auf dem Boden der antiken Anschauungen standen, Hypopyonoperation und Staarausziehung als völlig gleichstehende Operationen angesehen zu haben. So stellt z. B. Averrois (8)***) Hypopyon und Staar in einem

*) Lib. I, Cap. 45.

**) Tome II, p. 441.

***) Tractat. sept. 
Capital zusammen und die operative Entfernung beider aus dem Auge unterscheidet sich für ihn in ihrer Technik so wenig, dass er zwischen ihnen eine besondere Trennung nicht für nothwendig zu erachten scheint, vielmehr beide zusammen mit den Worten abfindet: Et aliqui sunt qui curant eas aperiendo.

Wir hoffen diese unsere Behauptung, welche auf die Frage nach der Existenz der Staarausziehung im Alterthum ein ganz eigenthümliches, wie uns dünken will, bisher noch nicht genügend gewürdigtes Licht wirft, im Lauf unserer kritischen Untersuchung noch durch einige, anderen Autoren entlehnte Stellen zu beweisen und sicher zu stellen. Bevor wir aber an eine weitere Prüfung dieser Stellen herantreten, wollen wir erst für die von uns versuchte Auslegung des Aelianus noch einen andern Gewährsmann, Rondeletius (40)*) hören. Derselbe äussert sich über die operative Behandlung des Staars bei den Alten wie folgt: "Solebant antiqui punctura hunc affectum (nämlich den Staar) curare (ut patet ex introductorio Gal. lib. ita inscripto) qui docent hane curationem fortuito inventam fuisse, quum capra pateretur hunc affectum et in aculeum incidisset. Perforata enim cornea effluxit aqua et curata est. Si quis moliri voluerit hanc curandi rationem, eo modo, quo pus extrahitur, non erit omnino absurdum." Es enthält diese Aeusserung des Rondeletius doch gewiss einen sehr deutlichen Hinweis auf eine zwischen der Hypopyonoperation und der Methode, nach der die Alten in gewissen Fällen Erkrankungen des Anges, die sie als Staar bezeichneten, zu operiren pflegten, herrschende Aehn. lichkeit. Die schliessliche vollständige Identität beider Methoden konnte aber Rondeletius natürlich noch nicht ahnen, da er ja mit seinen Anschauungen über

*) Cap. 55, p. 259. 
Natur und Wesen des grauen Staares noch durchaus auf antikem Boden stand.

Einen weiteren Beweis dafür, dass die Alten, ausser der Depression des Staares, woch eine andere Methode kannten, vermittelst der sie gewisse pathologische im Auge angehäufte Produkte, die sie Staar nannten, operativ aus dem Auge entfernten, liefort Galen $(17)^{*}$ ) die be-

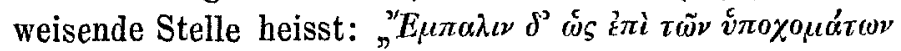

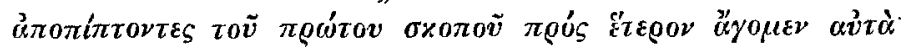

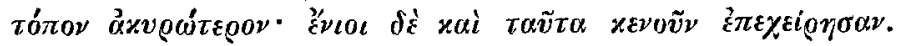
Versuchen wir eine Uebersetzung derselben, so würde diese lauten: „Was nun im Gegentheil den Staar anlangt, so führen wir denselben, wenn wir von der zuerst beabsichtigten Behandlungsmethode desselben (medicamentöse Behandlung) abgehen, an einen minder wichtigen Platz (im Auge). Einige versuchen es aber auch, den Staar zu entfernen, was wir in den chirurgischen Büchern besprechen wollen." Nun hier spricht doch Galen in so klarer und deutlicher Weise von zwei verschiedenen, bei den Alten üblichen Staaroperationsmethoden, von einer, bei der der Staar im Auge verblieb, und von einer, bei der er aus demselben entfernt wurde, dass ein weiterer Zweifel an dieser Thatsache wohl kaum noch eine Berechtigung beanspruchen dürfte.

Und auç für unsere Behauptung, dass die von den Alten geübte operative Entfernung des Staares aus dem Auge identisch sei mit unserer modernen Entleerung eines Hypopyon, vermag diese Stelle vielleicht gewisse Anhaltepunkte $z \mathfrak{u}$ liefern. Das Wort xavoör nämlich, mit dem Galen hier die Entfernung des Staares aus der

*) Method. med. Lib. XIV, Cap. 13, Sichel (p. 13) und Anagnostakis (p. 43) haben bereits anf Grund dieser Stelle die Behauptung ausgesprochen, dass die Extraction des Staares eine der antiken ophthalmologischen Chirurgie wohl bekannte Methode gewesen sei. Näheres über die Technik dieser Operation, sowie deren Indicationen haben aber jene beiden Autoren nicht ausgesagt. 
Bulbuskapsel bezeichnet, wurde von den Alten zwar sowohl von festen, wie auch von flüssigen Gegenständen gebraucht, doch scheint man in der antiken Medicin mit Vorliebe sich des Ausdruckes xєvõ̃v bedient zu haben, um die Entleerung flüssiger oder halbflüssiger Substanzen

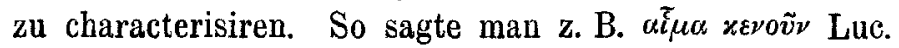
ocyp. 93. Auch für die Entleerung des schleimigen und halbflüssigen Augeninhaltes aus der Bulbuskapsel ge-

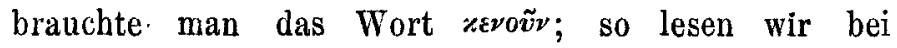
Pollux (38)*): „ڤं

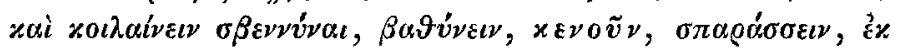

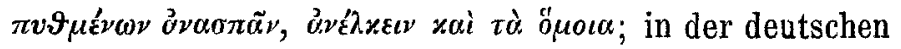
Uebersetzung würde diese Stelle lauten: „Man könnte auch sagen: die Augen ausstechen und ausgraben, austrocknen, aushöhlen, ausleeren, zerreissen, aus der Tiefe ziehen, in die Höhe ziehen, und dergleichen mehr." Genau in derselben Bedeutung gebraucht Pollux**)

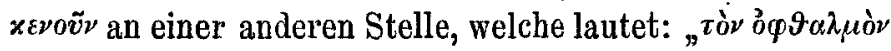

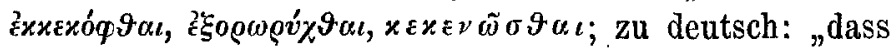
das Auge herausgeschlagen, ausgestossen, ausgeleert werde." Es soll also in diesen beiden Stellen mit dem Ausdruck $\chi \varepsilon \nu o \tilde{\nu}$ bezeichnet werden die Entleerung des schleimigen und halbflüssigen Augeninhaltes.

Vielleicht wäre es nun gestattet, im Hinblick auf diese Gebrauchsweise des Wortes xєvoṽ für die Entleerung schleimiger oder flüssiger Gegenstände, die Vermuthung zu äussern, dass auch Galen gerade den Ausdruck $x \in \nu o \tilde{v} \nu$ deshalb hier gewählt habe, um die schleimige, halbflüssige Beschaffenheit des Staares anzudeuten. Und diese Vermuthung gewinnt um so mehr an Wahrscheinlichkeit, wenn wir erwägen, dass die Alten, wie wir dies bereits im Vorangegangenen betont haben, und auf den

*) Vol. I, p. 89, II, 62.

**) Vol. I, p. 233, IV, 189. 
folgenden Blättern, noch ausführlicher begründen werden, die Ausziehung des Staares nur für flüssige, serösplastische Ansammlung in der vorderen Kammer angezeigt hielten.

Uebrigens können wir, halten wir nur die Thatsache unverrückt fest, dass die von den Alten geübte Extraction des Staares nichts wie eine Hypopyonpunction gewesen ist, vielleicht auch bereits bei Plinius einen Hinweis auf diese Methode finden. Lassen wir uns deshalb die Mühe nicht verdriessen, nochmals zu Plinius zurückzukehren. Lib. XI, 55 sagt er: „sed homo solus emmisso bumore caecitate liberatur. Post vicesimum annum multis restitutus est visus." Man wird mir einräumen, dass, erinnert man sich nur daran, dass die Alten gewisse Formen des Staares in der Weise zu operiren pflegten, dass sie die Flüssigkeit, die nach ihren pathologischen Begriffen den Staar verursachte, aus dem Auge entfernten, die Vermuthung, Plinius könne mit dieser Bemerkung vielleicht auf jene Operationsmethode angespielt haben, durchaus nicht eine ganz unbegründete und willkürliche sei, sondern ihr eine gewisse Berechtigung zugestanden werden müsse. Warum Harduin $(36)^{*}$ ) vor einer derartigen Auffassung dieser Stelle ganz ausdrücklich warnt, ist uns, offengestanden, nicht klar geworden; auch führt er keinerlei sachliche Gründe an, die ihn dazu veranlasst haben könnten, die in Rede stehende Stelle nicht auf den Staar zu beziehen. Dagegen sieht Daleca mp (35) $*$ ) in dieser Stelle einen directen Hinweis auf den Staar und auch Wallroth $\left.(49)^{* * *}\right)$ trägt keinerlei Bedenken, sie in directester Weise mit der Ausziehung des Staares in Verbindung

*) Band IV, p. 378.

**) p. 538.

***) p. 179 , 
zu bringen. Er sagt: "Nihilosecius tamen glaucomati per extractionis opus curandi modi prima vestigia, neque ex Davielis, neque ex Goskyi dexteritate petere, sed ab ipsa natura, aut casu instituti, in Plinii loco illo (XI, 55) quaerere mallem, qui saepe, sed in homine solummodo observavit, coecos emissis humoribus, coecitate post vigesimum quoque annum, liberatos esse."

Wenn wir nun auch nicht Anstand nehmen, mit Wallroth jene Stelle des Plinins auf ein Verfahren zu beziehen, mittelst dessen die Alten gewisse Ansammlungen in der vorderen Kammer, die sie Staar nannten, operativ aus dem Bulbus entfernten, so können wir ihm jedoch in keiner Weise beistimmen, wenn er in diesem Verfahren nun auch die ersten Anfänge unserer modernen Staarextraction erblicken will. Denn jene antike und unsere moderne Ausziehung des Staares haben mit einander durchaus nichts gemeinsam. Die von den Alten geübte Staarextraction war nichts, wie eine Hypopyonpunction, hatte mit der Erkrankung des Auges, die wir heute Staar nennen, gar nichts zu thun, sondern bezweckte lediglich nur, gewisse plastisch-seröse Ergüsse, welche die antike Okulistik aber dem Begriff Staar unterstellte, aus der vorderen Kammer wegzuschaffen.

Es liegt uns jetzt noch ob, jene beiden bekannten und viel verkannten Stellen aus dem Continens des Rhases $(39)^{*}$ ) einer Prüfung zu unterziehen und zuzusehen, in wieweit dieselben unsere Behauptung, die Alten haben zwar eine Extraction des Staares gekannt, doch war diese Extraction nichts anderes als die Hypopyonpunction der modernen Ophthalmologie, bestätigen.

Was zuerst die Stelle des Latyrion anlangt, so kann

*) Fol. 49b B. I a. Fol. 50 b B. I. Die zu Brixen 1486 erschienene Ausgabe des Continens des Rhases, die ich gleichfalls zu vergleichen Gelegenheit hatte, bringt die von uns citirten Stellen genau in demselben Wortlaut. 
ich Hirsch (27)*) nur aus vollem Herzen beistimmen, wenn er sie eine dunkle nennt und Bedenken trägt, sie in dem Wortlaut, in dem sie uns überkommen ist, so ohne Weiteres mit der Ausziehung des Staares in Zusammenhang zu bringen. Ja selbst jetzt, nachdem ich mich aus den Werken der Alten hinlänglich überzeugt zu haben glaube, dass die antike Oculistik eine operative Entfernung gewisser pathologischer Produkte, die sie als Staar auffasste, aus dem Auge gekannt und geübt habe, scheint es mir doch noch sehr fraglich, ob man wirklich berechtigt sei, in dieser Stelle einen Hinweis anf jene Extractionsmethode zu erblicken. Denn prüft man den Text der Stelle, welcher lautet: "Latirion dixit. Cum chirurgicus vult extrahere cataractam ferro debemus tenere instrumentum super cataractam per magnam horam in loco ubi ponitur illud" mit unpartheiischen Augen, so wird man mir einräumen müssen, dass die gesammte Stelle eigentlich nichts enthält, als den guten Rath bei der Depression des Staares die Nadel eine Zeit lang auf der niedergedrückten Linse ruhen zu lassen, um deren Wiederaufsteigen zu verhüten, einen Rath, dem wir bei den meisten, oder doch bei sehr vielen Autoren wieder begegnen, und dass, will man diese Stelle mit aller Gewalt auf die Ausziehung des Staares beziehen, man dies nur in der Weise ausführen kann, dass man das Wort extrahere, unbekümmert um den Sinn der gesammten übrigen Stelle herausreisst und nun behauptet, weil extrahere ausziehen heisse, müsse auch die gesammte Stelle auf die Ausziehung des Staares Bezug haben. Uebrigens hat bereits Hirsch (27)*) den Werth dieser Stelle und ihre Bedeutung für die Ausziehung des Staares in so treffender Weise beurtheilt und charakterisirt, dass wir es für das Gerathenste erachten, uns bei der kritischen

*) p. 289. 
Beleuchtung derselben an jenen bewährten Autor anzulehnen. Entweder bedeute, so meint Hirsch, extrabere hier gar nicht ein Ausziehen des Staares aus dem Auge, sondern nur ein Ausziehen desselben aus der Pupille, also nur eine Dislocation des Staares, oder die Stelle sei verstümmelt, und zwischen den Worten ferro und debemus sei ein Satz ausgefallen, der die nähere Manipulation der Ausziehung geschildert habe. Was nun die erste dieser beiden von Hirsch aufgestellten Möglichkeiten anlangt, dass extrahere hier gar nicht ein Ausziehen des Staares aus dem Auge, sondern nur aus der Pupille zu bedeuten habe, und dass somit die gesammte Stelle nur auf die Depression des Staares zu beziehen sei, so scheint uns dieselbe eine höchst glückliche Combination zu sein. Denn gerade sie lässt sich durch verschiedene, älteren wie neueren Autoren entlehnte Stellen, in denen direct extrahere, oder ihm verwandte Worte wohl für das Entfernen des Staares aus der Pupille, aber nicht aus dem Auge gebraucht werden, ganz mühelos und ungezwungen stützen. So findet sich im Rhases (39)*) selbst eine Stelle, in der extrahere in ganz zweifelloser Weise wohl von einem Entfernen des Staares von seinem gewöhnlichen Sitz, aber nimmermehr von einem Ausziehen desselben aus dem Auge gebraucht wird. Die betreffende Stelle steht kurz vor dem berühmten Citat des Latyrion und ist der Schilderung entlehnt, die Antyllus**) von der Depression des Staares entwirft, sie

*) Fol. $50 \mathrm{~b}$.

**) Ich will übrigens hier vorläufig mittheilen, dass besagte Stelle des Antyllus auch dadurch noch von ganz besonderer Wichtigkeit wird, dass in ihr unzweifelhafte Beweise dafür enthalten sind, dass die Alten ausser der Depression des Staares durch die Sclera noch eine andere Methode gekannt und geübt haben, bei der sie durch die Cornea in die vordere Kammer mit der Nadel eingingen und so die Depression vollzogen. Meist wählten sie für den Einstichspunkt den Corneo-Scleralfalz, oder 
lautet: „Et si cataracta erit difficilis: quod cum imprimitur inferius revertatur superius: trahatur ad partes ubi videbitur levius ad extrahendum donec videat patiens $a b$ ea hora: et cum perficitur hoc, extrahatur instrumentum foris." Nun ich meine, einen besseren and schlagenderen Beleg für die Vermathung von Hirsch, dass Latyrion mit dem Ausdruck extrahere nur die Entfernung des Staares von seinem Sitz, aber nicht aus dem Auge habe bezeichnen wollen, kann wohl kaum gefunden werden, und könnten wir uns an ihm eigentlich schon genügen lassen. Doch wollen wir, um zu zeigen, dass extrahere, sowie ihm verwandte Worte gar nicht selten gebraucht wurden, um die Dislocation des Staares von seinem ursprünglichen Sitz an einen anderen Punkt des Auges zu bezeichnen, noch einige andere einsehlägige Stellen anziehen.

Abynzoar (1)*) nennt die Depression des Staares geradezu Extraction und das Capitel, in dem er von der Niederdrückung des Staares handelt, trägt die Ueberschrift: „De extractione cataractarum ab oculis. Es lautet: "Oportet quidem ut extrahatur cataracta post ipsius perfectam digestionem et coagulationem: quoniam si ante feceris redibit aqua ut prius. Et cum dico extrahere cataractam intellige sane, quod impossibile est eam extrahere sicut multi crediderunt; sed profundatur cum acu inferius in spissitudinem oculi." Nun hier identificirt Abynzoar doch geradezu die Depression des Staares mit dem Ausdruck extrahere.

Ein dem Wort extrahere synonymes, oder doch we-

die Zone der Hornhaut, welche dicht vor dem Scleralfalz liegt. Es hat somit die Keratonyxis ein beträchtlich höheres Alter als man iht bisher zuzuschreiben gewillt war. Fine genauere Schilderung dieser Operationsmethode mit den erforderlichen Beweisstellen gedenke ich in meiner Geschichte des granen Staares zu liefern.

) Cap. 19, Fol. 7 . 
nigstens nahe verwandtes Wort gebraucht Galen (17)*), um die Entfernung des Staares von seinem ursprünglichen Sitz zu bezeichnen, nämlich $\pi \alpha \rho \alpha ́ \gamma \varepsilon \iota \nu$. Kühn übersetzt dasselbe mit educere, wobei ihm aber gewiss nicht eingefallen ist, ein Herausführen des Staares aus dem Auge selbst bezeichnen $\mathrm{zu}$ wollen.

Auch in älteren deutschen medicinischen Werken findet man gar nicht selten anstatt des Ausdruckes den Staar stechen, die Wendung den „Staar abnehmen" oder „abziehen vom Auge und dem Stern." Dass aber dabei die betreffenden Autoren nicht an ein wirkliches $A b-$ nehmen oder Abziehen des Staares vom Auge gedacht haben, wird wohl auch der peinlichste und gewissenhafteste Commentator nicht $\mathrm{zu}$ behaupten wagen, vielmehr woliten jene Autoren nur damit bezeichnen, dass der Staar von der Pupille abgezogen werde. Als Beweis hierfür möge man Bartisch (11) einsehen.

Und so müssen wir denn gestehen, dass wir im Hinblick auf diese Stellen, viel eher geneigt sind, das Citat des Latyrion einfach auf die Depression zu beziehen, als in ihm einen Hinblick auf die Extractionsmethode zu erblicken. Denn da es jetzt feststeht, dass man das Wort extrahere auch bei der Depression anzuwenden kein Bedenken trug, so sehe ich eigentlich nicht ein, warum man einen derartigen usuellen Gebrauch des Wortes extrahere auch hier anzunehmen nicht völlig berechtigt sein sollte. Und zwar um so mehr, da ja kurz vor der Stelle des Latyrion extrahere bereits bei der Niederdrückung des Staares gebraucht wird, wie wir dies soeben nachgewiesen haben.

Uebrigens würde auch das in Rede stehende Citat des Latyrion, wollte man dasselbe trotz unserer Polemik

*) De usu partium. Lib. X, Cap. IV. 
doch auf die Ausziehung des Staares beziehen, für die Lehre von der antiken Extraction durchaus keinen sonderlichen Werth beanspruchen können. Denn da, wie wir dies im Verlauf unserer Untersuchung nachgewiesen $z u$ haben glauben, bereits lange vor Laty rion die antike Extractionsmethode in Blüthe war, so würde jene Stelle in keiner Weise mehr als einer der ältesten Hinweise auf die Ausziehung gelten können, wie dies verschiedene Autoren bisher anzunehmen geneigt waren. Und damit erweist sich denn auch die von einzelnen Forschern (Hecker $(26)^{*}$ ), Kühn (28)**)) vertretene Ansicht, dass Latyrion der eigentliche Erfinder der Staarausziehung gewesen sein soll, als durchaus hinfällig. Uebrigens hat auch bereits Hirsch den Nachweis geliefert, dass die Behauptung, Antyllus habe dem Latyrion die Erfindung der Staarausziehung nachgerühmt, eine völlig müssige sei, welche sich durch den Wortlaut der im Rhases sich findenden bezüglichen Stellen in keiner Weise rechtfertigen lasse. Und da ferner die betreffende Stelle bei ihrer Verstümmelung uns auch keinerlei näheren Aufschluss über die Ausführung der antiken Ausziehung zn geben vermag, so wird auch nach dieser Seite hin ihr Werth und ihre Bedeutung durch einschlägige, aus älteren Autoren entnommene Stellen auf das Erheblichste überflügelt.

Eine um vieles wichtigere und bedeutungsvollere Rolle als das soeben kritisch untersuchte Citat des Latyrion spielt dagegen die bekannte Stelle des Antyllus $(39)^{* * *}$ ) in der Lehre von der antiken Staaraus. ziehung. Dean diese Stelle, welche lautet: „Et aliqui aperuerunt sub pupilla et extraxerunt cataractam: et

*) 2. Band, § 17, p. 61 .

**) VII, p. 3.

***) B. I, Fol. 50 b.

v, Graefe's Achiv für Ophthalmologie, XXII. 2. 
potest esse cum cataracta est subtilis: et cum est grossa non poterit extrahi: quod humor egrederetur cum ea. Et aliqui loco instrumenti posuerunt concilium vitreum: et sugendo eam surexerunt albugineum cum ea" giebt uns zugleich, sowohl über die Ausführungsweise der Ausziehung, als vor Allem über deren Indication einen Auf. schluss, der besonders was den letzteren Punkt anlangt, von der grössten Bedeutung ist. Doch werden wir, bevor wir an eine kritische Durchleuchtung der Stelle selbst herantreten, gut thun, erst die verschiedenen Irrthümer, die sich gerade in Betreff ihrer in einzelne Handbücher der Geschichte der Medicin eingeschlichen haben, zu berichtigen. Vor Allem müssen wir entschiedenen Widerspruch dagegen erheben, dass man Antyllus gar nicht selten als den Erfinder der Extraction verherrlicht, oder doch meint, er habe zuerst eine umständliche Peschreibung der Extraction gegeben. So sagt z. B. Lessing (29)*): „Antyllus ist besonders dadurch berühmt geworden, dass er zuerst die Extraction des Staares beschrieben hat." Auch Häser (21)**), einer der gewiegtesten Kenner der Geschichte unserer Wissenschaft, scheint von einer ähnlichen Ansicht auszugehen, wenn er die ersten unzweifelhaften Erwähnungen der Ausziehung des Staares bei Latyrion und Antyllus sucht. Haben wir doch lange vor Antyllus die Kenntniss der Extraction bei Aelianus und Galenus gefunden. Uebrigens ist bereits von einzelnen Forschern dieser Umstand in genügender Weise gewürdigt worden; so macht Lewy (30)***) ausdrücklich darauf aufmerksam, dass Antyllus nicht, wie man so häufig irrthümlich behaupte, die erste umständliche Schilderung der Extraction biete, vielmehr eigentlich nur eine kurze Erwähnung derselben. Und

*) 1. Band, p. 126.

**) 1. Band, p. 524 .

***) 2. Band, 4, Heft, p. 757 . 
Hccker (26)*) datirt die ersten Anfänge der Staarausziehung auf mehr denn hundert Jahre vor Antyllus zurück. Unsere Untersuchung hat diesen Streit, der unter den verschiedenen Autoren über die Prioritätsrechte, die Antyllus in Betreff der antiken Staarausziehung beanspruchen darf, so hoffen wir, geschlichtet und nachgewiesen, dass schon lange vor der Zeit des Antyllus die antike Ausziehungsmethode des Staares eine sehr wohl gekannte Operation gewesen sei.

Unser besonderes Befremden erregt aber die Schilderung, dieS p r engel (44)**) von der Ausziehungsmethode des Antyllus entwirft und die Bernstein (12)***) von ihm entlehnt zu haben scheint. Sprengel sagt nämlich: „Erst öffnet Antyll us die Hornhaut, dann bringt er eine feine Nadel durch die Pupille in die verdunkelte Krystalllinse, dreht etwas und zieht sie dergestalt durch dic Oeffnung der Cornea hervor." Ein Blick auf den von uns citirten Wortlaut der betreffenden Stelle zeigt, dass dieselbe auch nicht die leisesten Andeutungen eines derartigen Operationsverfahrens enthält, wie es hier Sprengel beschreibt. Uns will es fast scheinen, als ob Sprengel bei diesen seinen Angaben durch ein Missverständniss irre geleitet worden sei, und die Stelle des $\mathrm{Rhases,}$ welche die Schilderung der von Antyllus geübten Depression enthält, auch auf die Extraction bezogen habe. Und zwar wird dies Missverständniss einigermassen erklärlich, wenn wir bemerken, dass diese Stelle nicht das gewöhnliche, aus Celsus bekannte Depressionsverfahren schildert, sondern ein von diesem wesentlich abweichendes, bei dem die Depressionsnadel nicht durch die Sclera in den Bulbus geführt, sondern vielmehr durch den Cornealfalz in die vordere Kammer gestochen wurde; An-

*) 2. Band, § 17, p. 60 .

**) 1. Band, Cap. II, $\S 3$, p. 51.

***) 1. Theil, p. 53. 
tyllus sagt ganz ausdrücklich: ,et perforetur conjunctiva et cornea." Doch muss ich mir es versagen, hier näher auf diese eigenthümliche Depressionsmethode einzugehen, mich vielmehr damit begnügen, auf meine demnächst erscheinende Geschichte des grauen Staares hinzuweisen, welche die nöthigen Erlklärungen über diesen Punkt bringen wird.

Ein anderer, viel verhängnissvollerer und folgenschwerer Irrthum, dem es hauptsächlich zuzuschreiben ist, dass unan die von Antyllus geschilderte antike Extraction mit der modernen identificirt hat, liegt in der schiefen und unrichtigen Uebersetzung der Worte: „et potest esse cum cataracia est subtilis: et cum est grossa non poterit extrahi." Denn indem man subtilis mit "klein" und grossa mit "gross" übertrug (Lessing, Lew y u. A.), glaubte man, Antyllus hätte durch diesen Zusatz bemerklich machen wollen, dass der Staar nur dann durch Ausziehung operirt werden könne, wenn er von kleineren Dimensionen sei, während er bei grösserem Umfang nur durch Depression zu beseitigen sei. So sagt z. B. Gross (19)*): „Mox de utilitate cataractae extrahendae et deprimendae cogitatum atque existimatum est, extractionem tantum perficiendam esse, cum cataracta parva sit." Bei einer derartigen Uebersetzung hat man sich aber offenbar viel zu sehr von den Vorstellungen leiten lassen, welche die moderne Ophthalmologie von der Natur des Staares hat und dabei vollständig unberïck. sichtigt gelassen, in welcher Bedeutung jene beiden Worte, gerade zu der Zeit gebraucht wurden, in welcher der Continens des Rhases übersetzt und gedruckt wurde. Und doch werden wir ein richtiges Verständniss jener beiden Ausdrücke nur in der Weise zu gewinnen in-Stande sein, dass wir uns auf das Genaueste unter-

*) p. 30 . 
richten, in welchem Sinn und in welcher Bedeutung gerade zu der Zeit, als der Continens übertragen wurde, die Ophthalmologie dieselben gebrauchte. Denn es steht doch wohl zu erwarten, dass der betreffende Uebersetzer und Herausgeber des Rhases mit jenen beiden Worten genau denselben Sinn und dieselbe Bedeutung verknüpft habe, welche gerade zu seiner Zeit gebräuchlich und üblich gewesen sind; besonders wenn diese Worte, wie dies bei subtilis und grossa zu jener Zeit der Fall gewesen sein dürfte, gleichsam als Termini technici eine ganz charakteristische und specifische Bedeutung erlangt hatten. Durchblättern wir nun, um uns eine genaue Kenntniss von der Bedeutung, in der subtilis und grossa in jener Periode gebraucht wurden, die medicinischen Werke jenes Zeitabschnittes, so werden wir bemerken, dass die medicinischen Autoren damals fast allgemein mit subtilis und grossa durchaus nicht den Umfang und die Grösse des Staares, also nicht seine Quantität zu bezeichnen pflegten, sondern mit diesen Worten, wenn wir so sagen dürfen, die Aggregatzustände des Staares kennzeichneten. Bekanntlich hielten ja die Alten sowohl wie im engsten Anschluss an sie auch die Autoren des Mittelalters den Staar für eine Flüssigkeit, die sich im Auge anhäufte und durch ihre Gerinnung schliesslich das Staarfell erzenge. Diese verschiedenen Gerinnungsgrade des Staares nun suchten die Autoren jener Zeit mit subtilis und grossa zu charakterisiren; und zwar in der Weise, dass sie mit subtilis jene Anfangsperiode des Staares zu kennzeichnen suchten, in der er noch nicht geronnen, sondern noch flüssig sei, seine einzelnen Partikelchen noch nicht $\mathrm{zu}$ einem zusammenbängenden, festen Gewebe geeint wären; mit grossa dagegen jene Phase bezeichneten, in der er bereits zu einer compacten Masse sich geronnen zeigte. Wir können diese unsere Behauptung auf das Schlagendste durch einen Vergleich 
der lateinischen Uebersetzung des Avicenna (9)*) mit dem arabischen Text (10)**) desselben, welche uns beide vorliegen, beweisen. In der lateinischen Ausgabe finden sich nämlich die Ausdrücke subtilis und grossa, und sollen durch sie gewisse Eigenschaften der Qualität des Staares bezeichnet werden. Im arabischen Text nun aber lautet das Wort, das der mittelalterliche Ueber-

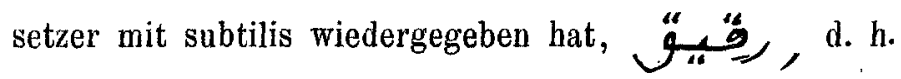
dünn, und das, welches er mit grossa übertragen hat, dis d. h. dicht. Hiernach kann also nicht davon die Rede sein, jene beiden Ausdrücken, welche mit subtilis und grossa vom Uebersetzer wiedergegeben sind, auf den Umfang und die Grösse des Staares beziehen zu wollen, vielmehr sind dieselben offenbar nur darauf berechnet, bestimmte Aggregatzustände jenes Ergusses, den man als Staar ansprach, anzuzeigen.

Genau in derselben Weise gebraucht auch Petrus von Largelata $(34)^{* * *}$ ) subtilis nur, um gewisse Aggregatzustände der Staarsubstanz zu charakterisiren und zwar gerade jene erste Phase, in der sie noch flüssig ist; deshalb fügt er zu subtilis auch noch das Wort mobilis hinzu. Valescus de Taranta (47)†) benutzt subtilis und grossa gleichfalls, um gewisse Zustände der Qualität des Staares anzudeuten. Galeatius de sancta Sophia (16) ††) unterscheidet am Staar drei Phasen; in der ersten nennt er ihn subtilis und bemerkt ausdrücklich, in diesem Zustand könne er niemals niedergedrückt

*) Lib. III, Fen. III, Tractatus IV, Cap. 18.

**) Lib. III, Tract. IV, Fen.III, p. 352. Cap.: Ueber den Staar, lin. 9 von unten. Die Uebersetzung der betreffenden Stelle verdanke ich meinem Vater'Dr. E. Magnus, ord. Prof. der oriental. Sprachen an der Universität Breslan.

***) Lib. V, Tract. VII, Cap. II, Fol. 98.

†) Cap. 29, Fol. 36.

t†) Cap. 27, Fol. 22. 
werden, da er noch zu weich sei und so der Nadel nicht den genügenden Widerstand zu bieten vermöge; die zweite Phase bezeichnet Galeatius als media und meint, in dieser habe der Staar gerade den richtigen Grad der Gerinnung erreicht, um mit Vortheil operirt werden zu können; während er dagegen in der dritten Phase, welche den Namen grossa trägt, schon zu hart geworden und mit seiner Umgebung zu stark zusammengeklebt sei, um sich noch mit Aussicht auf Erfolg niederdrücken zu lassen.

Und dass auch in dem Citat des Antyllus die Ausdrücke subtilis und grossa nur gewisse Aggregatzustände der Staarsubstanz bezeichnen sollen und zwar subtilis den der noch nicht eingetretenen, grossa aber den der vollendeten Gerinnung, lässt sich in directester Weise aus dem Continens selbst beweisen. Denn Fol. 47 findet sich eine dem Antyllus entlehnte Stelle, die lautet: „Et illa(nämlich Cataracta) curatur cum perforatione quae est temperatae congelationis : et quae est fortis congelationis et nimis subtilis non curatur perforatione." Nun ich meine einen noch schlagenderen Beweis dafür, dass subtilis nicht die Grössenverhältnisse des Staares, sondern ausschliesslich nur seinen Aggregatzustand bedeutet habe, können wir wohl nicht führen. Versuchen wir jetzt, im Besitz dieser Erkenntniss, eine Uebersetzung jener Stelle: „Et potest esse cum cataracta est subtilis et cum est grossa non poterit extrahi" so würde dieselbe lauten: „Und es kann eine Ausziehung des Staares nur stattinden, wenn er flüssig ist, aber nicht wenn er geronnen ist." Und dass wir mit einer solchen Uebersetzung dem Sinn der gesammten Stelle in sehr glücklicher Weise Rechnung getragen und die Indicationen, welche die Alten für die Ausführung ihrer Staarausziehung hatten, in der treffendsten Weise charakterisirt haben, vermögen wir auch noch daraus zu erkennen, dass einzelne namhafte Autoren des Mittelalters, die doch in ihren medicinischen $\mathbf{A n}$ - 
schaungen, wenigstens soweit es die Lehre vom Staar anlangt, durchaus auf antikem Boden standen, als wichtigste Indication für die Staarausziehung den flüssigen Zustand des Staares bezeichneten. So sagt $z$. B. Arculanus $\left.(7)^{*}\right)$ : „Non omnis cataracta curatur per sectionem corneae, sed solum illa quae est immediata ipsi corneae et quae est fluida." Nun, einen derartigen Zustand nennen wir aber eben nicht Staar, sondern ein Hypopyon.

Jetzt wird man wohl aber kaum mehr eines besonderen kritischen Scharfblickes benöthigen, um zu erkennen, dass die von Antyllus erwähnte antike Staarausziehung mit der modernen durchaus nichts gemeinsam habe, vielmehr nichts weiter sei, als der Hinweis auf ein Operationsverfahren, mittelst dessen die alte Okulistik gewisse plastisch-seröse Exsudate der vorderen Kammer aus dem Auge entfernte; ein Operationsverfahren, das wir bereits aus den Andeutungen des Aelian und Galen kennen gelernt haben. Wenn man aber diese Operationsmethode bis jetzt einfach mit der unserer modernen Extraction identificirte, und in jener nur die ersten Anfänge dieser erblicken wollte, so hat man sich offenbar durch den Umstand dazu verleiten lassen, dass die Alten plastisch seröse Ansammlungen in der vorderen Kammer als Staar ansahen und gemäss dieser ihrer pathologischen Vorstellungen da von einer Extraction des Staares sprachen, wo wir heut zu Tage nur von einer Hypopyonpunction reden würden. Man hat eben nicht genügend darauf geachtet, dass diejenigen pathologischen Zustände des Auges, in denen die antike Okulistik die Indicationen zu einer Staarausziehung erblickte, nach unseren modernen und geläuterten $\mathrm{An}$ schaungen mit dem Staar gar nichts gemein haben, an

*) Cap. XXX, p. 56. 
eine ganz andere Stelle unseres pathologischen Systems gehören, als in die Lehre vom grauen Staar.

Teberblicken wir nun nochmals die Resultate, welche wir in dem vor uns liegenden Abschnitt erreicht haben, so würden sich dieselben in folgende Sätze zusammenfassen lassen:

1) Die antike Okulistik kannte eine Extraction ge* wisser von $\mathrm{ihr}_{\uparrow}$ als Staar bezeichneter Ansammlungen pathologischer Produkte des Auges.

2) Diese von den Alten geübte Staarausziehung hat mit der modernen Extraction des grauen Staares nur das Bestreben gemein, das pathologische, die Function des Auges störende Produkt aus dem Auge zu entfernen. Da dies Bestreben aber sich auf das Genaueste der Natur und dem Sitz des Staares anzupassen suchen unusste, so konnte bei der so überaus verschiedenen Beschaffenheit dessen, was die antike und dessen, was die moderne Augenheilkunde als Staar bezeichnet, natürlich auch die Technik beider Operationsmethoden nur eine durchaus verschiedene sein.

3) Die antike Staarextraction muss als eine Operation angesehen werden, die unserer heutigen Hypopyonpunction gleichwerthig ist.

4) Die antike Staarextraction darf deshalb durchaus nicht als eine Vorstufe unserer modernen Staarausziehung angesehen werden.

Es kann hiernach wohl nicht mehr die Rede davon sein, dass, wie dies Hasner $\left.(25)^{*}\right)$ glaubt, bereits im Alterthum ein erheblicherer Streit zwischen Depression und Extraction entbrannt sei. Die antike Extraction war offenbar eine Operation, die sich innerhalb so beschränkter Indicationen bewegte, dass die alten Operateure gewiss nicht darau denken konnten, sie zur

*) pag. 3. 
alleinigen Methode zu erheben, oder durch sie der Depression eine bedenkliche Concurrenz zu schaffen. Sie war eben nur für ganz bestimmte Staarformen der alten Okulistik brauchbar, wie dies zur Genüge aus den Werken der Alten selbst herrorgeht, konnte also als ebenbürtige Rivalin der Depression nimmermehr auftreten.

\section{Abschnitt.}

Die Technik der antiken Extraction.

Ueber die Art und Weise, in welcher die Staarausziehung von den Alten geübt wurde, besonders über die Stelle, all der sie die Bulbuskapsel eröffneten, um das pathologische Produkt zu entfernen, erhalten wir gerade von den Autoren, welche der Extraction gedenken, keinerlei Aufschluss. Denu aus der kurzen Bemerkung des Antyllus: „Et aliqui aperuerunt sub pupilla" lässt sich doch gewiss nicht erkennen, wo eigentlich diese Einstichs- oder Einschnittsstelle lag; ob etwa dicht unter der Pupille, in dem mittleren Theil der Hornhaut, oder vielleicht mehr excentrisch, in der peripheren Cornealzone. Und Aelianus, Plinius, sowie Galenus geben über die Gegend des Auges, in der jene Operation vorgenommen $\mathrm{zu}$ werden pflegte, auch nicht die geringsten Andeutungen. Trotzdem dürtte es aber vielleicht doch möglich sein, über die Operationstechnik der antiken Extractionsmethode einigen Aufschluss zu erlangen. Halten wir nur fest, dass die Alten Hypopyon und Hypopyonpunction vielfach mit Staar und Staarausziehung zusammenwarfen und identificirten, so wird sich ein Weg, auf den wir den gewünschten Einblick in die Technik der antiken Extraction zu erlangen vermögen, 
doch vielleicht in der Weise finden lasseu, dass wir das Operationsverfahren, welches die Alten bei dem Hypopyon einzuschlagen pflegten, sowie die Grundsätze, nach denen sie jede operative Behandlung der Hornhaut überhaupt regeiten, einer genauern Prüfung unterwerfen und zusehen, ob wir hier nicht gewisse, auch für die Ausführung der antiken Staarausziehung wichtige allgemeine Gesichtspunkte zu gewinnen im Stande sind.

Einer sehr klaren und höchst charakteristischen Schilderung der Hypopyonpunction begegnen wir bei Galen (17)*). Hiernach pflegten die Alten die Hornhaut dicht vor dem Corneo-Scleralfalz, welcher bei den Griechen (41)**) $\Sigma_{\tau \varepsilon q u ́}{ }^{*} \eta \eta$, bei den Römern Corona hiess, zu öffnen. Dies scheint die allein übliche Methode gewesen $\mathrm{zu}$ sein; wenigstens habe ich bei keinem anderen Autor eine Andeutung oder Beschreibung einer anderen Hypopyonoperation gefunden. Auch Aëtius (3)***) und Paulus von Aegina (33) †) enthalten nur die bereits yon Galen gegebene Beschreibung. Auch in die arabische chirurgische Okulistik dürfte diese Operationsmethode des Hypopyon übergegangen sein, wie man aus dem Albucasis (4) †) ersehen kann. Und in der abendländischen Chirurgie scheint sich genau dieselbe Operationstechnik bis tief in das Mittelalter binein erhalten zu haben; so finden wir sie in derselben Weise wie sie bereits Galen geschildert, z. B. bei Brunus $(14) \dagger+$ ) wieder.

Es scheint also fast so, als wenn die Alten erhebliche Bedenken getragen hätten, die Cornea in ihrer

*) Method. med. Lib. XIV, Cap. 19.

**) Lib. I, Cap. V, p. 102.

***) Tetr. II, Sermo III, Cap. 28, p. 309.

†) Lib. III, Cap. XX, p. 576.

††) Tom. I, Lib. II, Sect. XXII, p. 167.

$++f)$ Lib. II, Rubrica X, Fol. 87. 
Totalität zu eröffnen, vielmehr jener Methode, welche die Oeffnung der vorderen Kammer dicht vor, oder gar im Corneo-Scleralfalz lehrte, unbedingt den Vorzug gegeben hätten. Die Beweggründe, welche sie hierbei leiteten, wurzelten offenbar ganz ausschliesslich in ihren physiologischen Vorstellungen, und zwar in erster Linie wohl darin, dass sie von einem umfangreichen Verlust des Kammerwassers einen erheblichen Schaden für die Leistungsfähigkeit des Auges befürchteten. Denn wenn die Autoren des Alterthums auch wiederholentlich die Erfahrung gemacht hatten, dass der Verlust des Kammerwassers sich in einiger Zeit ersetze und sogar diese Erfahrung, wie es den Anschein hat, auch durch Experimente an Thieren zu erbärten bestrebt gewesen sind man vergleiche über diesen Gegenstand Haller $(22)^{*}$ ), der die einschlägigen Stellen aus den Werken der Alten in sehr instructiver Weise zusammengestellt hat - so hatten sie doch diese Erfahrung nicht in dem Grade zu verallgemeinern gewagt, dass sie den vollständigen Verlust des Kammerwassers, geschah derselbe nun in Folge eines pathologischen Processes, oder in Folge eines operativen Eingriffes, als etwas durchaus Unschädliches betrachtet hätten. Im Gegentheil hielten sie den Verlust des Humor aqueus für einen sehr fatalen und bedenklichen Zufall, von dem sie anzunehmen geneigt waren, dass er die Leistungsfähigkeit des Auges auf das Erheblichste zu schwächen vermöge. Diejenigen Fälle aber, in denen sie einen Verlust der Kammerflüssigkeit ohne dauernde Beeinträchtigung des Sehvermögens beobachtet hatten, hielten sie für äusserst glückliche Zufälle, die sich aber, so meinten sie, nur höchst selten zu ereignen pflegten, und deshalb nur als Ausnahme von der allgemein gültigen Regel, vollständiger Verlust des Humor

*) Tom. V, Lib. XVI, Sect. II, p. 411. 
aqueus erzeuge unheilbare Blindheit, gelten dürften. Deshalb hält auch Galen (17)*) alle Hornhautwunden, die den mittleren Theil derselben betreffen, für sehr verhängnissvoll und glaubt, dass sie grösstentheils zu Blindheit führen müssten. Er hat zwar selbst einen Fall beobachtet, in dem ein Knabe, der sich rie Hornhaut gerade im Centrum perforirt hatte, keinerlei dauernde Beeinträchtigung in dem Sehvermögen des verwundeten Auges davongetragen hatte, doch sagt er ganz ausdrücklich, derartige Fälle seien selten und Blindheit meist die Folge solcher Verwundungen. Ganz in Uebereinstimmung mit diesen Ansichten findet sich in einem anderen, dem Galen (17)**) zugeschriebenen Buch, die Bemerkung, es wäre um Vieles vortheilhafter, wenn eiternde Geschwüre der Hornhaut nicht im centralen Theil derselben sässen, da bei einem solch' centralen Sitz bei einer operativen Behandlung des Geschwüres leicht das Kammerwasser abfliessen könnte. Und Oribasius (32)***) macht ganz ausdrücklich daranf aufmerksam, dass bei Operationen des Auges, speciell bei Punctionen, ein allzu reichlicher Abfluss des Kammerwassers Blindheit erzeuge. Die Gefahren, welche man aus einem vollständigen Verlust des Kammerwassers herleiten zu müssen glaubte, drohten hauptsächlich der Linse, nach den Anschauungen des Alterthums und Mittelalters dem eigentlichen und ausschliesslichen Sitz des Sehvermögens. Man fürchtete als unmittelbare Folge des vollständigen Abflusses des Kammerwassers Vertrockung der Linse, einen Zustand, den man Glankoma, auch wohl Glaucedo nannte, and für völlig unheilbar erachtete. Und wie tief die Gemüther in diesen Vorstellungen befangen waren, geht daraus

*) De symptomatum causis, Lib. I, Cap. 2.

**) De oculis, Cap. 10.

***) Medic. collect., Lib. XXIII, Cap. IV, p. 528. 
hervor, dass selbst bis tief in das Mittelalter hinein die Gefahr des Kammerwasserabflusses in der chirurgischen Okulistik eine sehr einflussreiche Rolle $\mathfrak{z u}$ spielen im Stande war.

Es konnte natürlich nicht ausbleiben, dass derartige physiologische Anschaungen auch auf die praktische Augenheilkunde jener Zeit den bedeutendsten Einfluss ausübten, und die operative Thätigkeit der griechischen und römischen Augenoperateure in der erheblichsten Weise beschränkten. Wir sind deshalb auch gewiss zu dem Schlusse berechtigt, dass, wie die Operateure jener Periode sich bei der Technik der Hypopyon-Operation völlig von ihren physiologischen Vorstellungen über die Gefahren des Kammerwasserabflusses leiten und beherrschen liessen, sie dies in derselben Weise wohl auch bei Ausführung ihrer Staarextraction werden gethan haben, eine Operation, die überdies noch dazu der Hypopyonoperation so überaus nahe stand. Wir dürfen uns aus diesem Grunde auch nicht zu der Aunahme verleiten lassen, dass die alten Augenärzte bei ihrer Staarextraction behufs Entfernung des pathologischen Produktes aus dem Auge eine ausgiebige Eröffnung der Bulbuskapsel vorgenommen und eine grössere Incision der Hornhaut ausgeübt hätten; etwa in der Weise, wie die moderne Okulistik beì der Staarausziehung verfährt. Eine solche Vorstellung, die man übrigens wohl doch oft genug gehabt zu haben scheint, wenn man die antike und moderne Staarextraction $z u$ identificiren kein Bedenken trug, würde auf einer durchaus irrthümlichen Grundlage beruhen und ein völliges Verkennen der bei den alten Ophthalmologen herrschenden physiologischen Anschauungen voraussetzen. Vielmehr war es bei Ausführung der Staarausziehung genau so, wie auch bei der der Hypopyonpunction, eine der Hauptsorgen der alten Operateure, jeden, nur einigermassen umfangreichen Verlust des Kammerwassers za 
vermeiden. Ijiess sich ein solcher nicht umgehen, so verzichteten sie lieber ganz auf die Ausziehung und gaben der Depression den Vorzug, wie dies ja auch aus der Stelle des Antyllus selbst hervorgeht, wenn er sagt: einen festen Staar kann man aber nicht ausziehen, da hierbei das Kammerwasser mit abfliessen würde. Und welche Verbreitung diese Furcht vor dem Verlust des Humor aqueus bei der Staarausziehung gehabt, und in welcher umfangreichen Weise sie auf das Operationsverfahren der alten Aerzte gerade auch bei Ausübung dieser Operation bestimmend eingewirkt haben muss, geht auch daraus hervor, dass wiederholentlich von den arabischen Aerzten der Abfluss des Kammerwassers als ein besonders gefährlicher Zufall der Staarausziehung bezeichnet wird, und dass die Besorgniss vor demselben nicht allein in die Augenheilkunde des Mittelalters überging, sondern auch in ungeschwächter Kraft sich noch $z u$ erhalten verstand, zu einer Zeit, wo bereits geläutertere Anschauungen über die Bedeutung des Kammerwassers sich geltend zu machen begonnen hatten. So hebt z. B. noch Savonarola (42)*) die bei der Staarausziehung drohende Entleerung des Kammerwassers als einen ganz besonders bedenklichen und gefährlichen Umstand hervor.

Wir sind hiernach also zu der Annahme gezwungen, dass die griechischen und römischen Augenoperateure bei der Ausziehung des Staares eine nur kleinc und wenig ausgiebige Oeffnung der Hornhaut gemacht haben und zwar entweder im Corneo-Scleralfalz selbst, oder doch dicht vor ihm; eine Oeffnung, die ihrer Lage und ihrem Umfang nach von der, bei der Hypopyonoperation üblichen sich wohl kaum wesentlich unterschieden haben dürfte. Ich bin um so mehr geneigt, die Einstichsstelle

*) p. 88 . 
bei der antiken Extraction im Scleralfalz zu suchen, als ja die ältere Ophthalmologie sich auch bei einer gewissen Methode der Depression - wie wir dies schon wiederholentlich im Lauf unserer Arbeit angedeutet haben - des Corneo Scleralfalzes zum Einbringen der Nadel in die vordere Kammer bediente, mithin die Aerzte jener Zeitepoche mit chirurgischen Manipulationen in der Gegend des Scleralfalzes vollkommen vertraut gewesen sein müssen. Und zwar wurde die Einstichsstelle, wie dies nicht allein aus der Beschreibung des Antyllus, sondern auch aus den Bemerkungen anderer Autoren so z. B. des Avicenna hervorgeht, in der unteren Hälfte des Scleralfalzes gewählt und zwar wohl meist an der, äusseren Seite der Hornhant.

\section{Abschnitt.}

\section{Die Aussaugung des Staares.}

Wir dürfen unsere Untersuchung nicht zum Abschluss bringen, ohne die Aussaugung des Staares, die im Grunde genommen nur eine Modifikation der antiken Staarausziehung bildet, einer, wenn auch nur kurzen Betrachtung gewürdigt zu haben. Während einzelne Autoren ihre Erfindung den Griechen zuschreiben und ihre ersten Spuren in der bekannten, die antike Extraction schildernden Stelle des A ntyllus suchen, nimmt Sichel (43)*) sie für die arabische Augenheilkunde in Anspruch und glaubt ihre Heimath nach Persien ver-

*) Band XIV, Abth. III, p. 12 u. 13. 
legen za müssen. Doch will es uns fast bedünken, als ob Sichel für diese seine Behauptung denn doch nicht völlig genügende und wirklich beweisende Gründe beigebracht habe. Denn da die bekannte Stelle des Antyll us über die Ausziehung des Staares mit den Worten schliesst: „Et aliqui loco instrumenti posuerunt concilium vitreum et sugendo eam surexerunt albugineum cum ea" so hat die Annahme, dieser Schlusssatz sei, in gleicher Weise wie der gesammte Wortlaut der ihr vorhergehenden Stelle, den Werken des Antyllus entnommen, wie mir scheinen will, denn doch eine gewisse Berechtigung. Und diese Berechtigung wird, so weit ich mir ein Urtheil erlauben will, durch die, von keinerlei Gründen gestützte Behauptung Sichel's: „Die Worte: Et aliqui beweisen deutlich, Rhases babe nicht daran gedacht, die Aussangung dem Antyllus als Erfinder zuzuschreiben" denn doch nicht aufgehoben oder entkräftet. Denn uns wird es durchaus nicht klar, warum und in welcher Weise Sichel in den Worten „Et aliqui” einen deutlichen Beweis dafür zu erblicken vermag, dass dieselben nicht dem A ntyllu s, sondern dem Rhas es zugeschrieben werden müssten, also nichts anderes seien, als eine Bemerkung des Rhases zu dem Citat des Antyllus. Gerade im Gegentheil scheinen uns diese, den Schlusssatz über die Aussaugung einleitenden Worte in der vollsten und glücklichsten Uebereinstimmung mit der Schreibweise der gesammten Stelle zu stehen. Denn fängt ja doch das ganze Citat gleichfalls mit den Worten „Et aliqui" an. Und dann, so sollte man doch vermuthen, würde Rhases diesen Schlusspassus, enthielte er nur seine eigene Bemerkung und nicht ein Citat aus A ntyllus, nicht so ohne Weiteres auf das Conto des Antyllus gesetzt, vielmehr denselben mit den einleitenden Worten: „Rhases dixit” oder "Dico" als sein persönv. Graefe's Archiv füir Ophthalmologie, XXII. 2. 
liches Eigenthum reclamirt haben. Und zwar gewinnt diese Vermuthung um so mehr an Wahrscheinlichkeit, wenn wir bemerken, dass $\mathrm{Rh}$ ase $\mathrm{s}$ an den verschiedensten Stellen des Continens Zusätze und Bemerkungen, die sein eigenes geistiges Produkt waren, meist durch die hinzugefügten Worte: "Rhases dixit” oder „Dico" kenntlich zu machen pflegte. Wir zögern daher nicht, denen, welche die ersten Spuren der Aussangung bereits bei den Griechen, speciell bei Antyllus suchen, eine grössere Berechtigung zuzugestehen, als wie Sichel, der ihr Entstehen erst in das 9. Jahrhundert verlegt und sie in Persien sich entwickeln lässt.

Schliesslich können wir uns auch der Finsicht nicht verschliessen, dass die Aussaugung des pathologischen Produktes, das die Alten Staar nannten, eine fär die Ausziehung desselben durchaus nothwendige und unerlässliche Ergänzung bilden musste. Vergegenwärtigen wir uns nur, dass die griechischen und römischen Aerzte unter dem Bann der Furcht vor dem Ausfluss des Kammerwassers stehend, keine ausgiebigere Eröffnung der Hornhaut wagten, vielmehr nur einen möglichst peripher gelegenen, wenig umfangreichen Einstich in die Cornea gestatteten und wir werden uns der Bemerkung nicht zu entschlagen vermögen, dass die alten Aerzte bei einer solchen Operationstechnik wohl of genug in die Verlegenheit gerathen sein mögen, die pathologischen Ansammlungen, die sie aus dem Auge zu entfernen bestrebt waren, nicht in genügender Weise entleeren zu können. Denn die enge, wenig ausgiebige Hornhautöffnung wird nur solchen Produkten den Durchgang gestattet haben, die nicht allzu dickflüssig und zäh gewesen sind. Hatten dieselben aber eine solche Consistenz nicht, waren sie vielmehr zähe, stärker geronnen nnd darum dickflüssiger - ein Zustand, den wir ja bei 
Hypopyen gar nicht selten zu beobachten Gelegenheit haben - so werden sie durch die enge Hornhautöffnung gewiss nicht im Stande gewesen sein, die Bulbuskapsel zu verlassen. Für solche Fälle nun, in denen der Operateur, wusste er nicht auf irgend eine andere Weise Rath zu schaffen, die für die Staarausziehung bestimmte Cornealöffnung ganz umsonst angelegt haben würde, bildete die Aussaugung des Staares, so will es mir scheinen, eine Aushülfe, erweiterte und vervollständigte die nicht ausreichende Extractionsmethode. Hier setzte der Operateur an Stelle des Instrumentes, mit dem er die Hornhaut eröffnet hatte, ein gläsernes Röhrchen, Antyllus sagt: „et aliqui posuerunt loco instrumenti concilium vitreum" und suchte nun durch Saugen die zähen und dickflüssigen Flocken des Ergusses aus der vorderen Kammer zu entfernen.

Es bildete somit die Aussaugung eine naturgemässe Vervollständigung und Erweiterung der antiken Staarausziehung, die sich schnell genug, sobald man nur eben die Ausziehung zu einer Methode erhoben hatte und sie auch methodisch in Anwendung brachte, auf dem Wege des zwingenden Bedürfnisses entwickelt haben dürfte. Und deshalb glaube ich auch, dass die Alten zur Zeit des Antyllus, also zu einer Zeit, in der sie, wie wir dies im Lauf unserer Untersuchung festgestellt haben, schon seit Jahrhunderten die Staarausziehung übten, auch sthon die Aussaugung gekannt und angewandt haben müssen. Und dass die Aussaugung und Ausziehung plastisch-seröser Ansammlungen aus der vorderen Kammer bei der von den Alten geübten Technik in einem äusserst nahen, wenn man so sagen darf, organischen Zusammenhang gestanden haben müssen, scheint mir auch daraus hervorzugehen, dass man bei einzelnen Schriftstellern des Mittelalters, die in ihren ophthalmologischen Anschauun- 
gen sich auf das Engste an die Alten anlehnen, einen directen Hinweis auf solch' ein enges Abhängigkeitsverhältniss zwischen Staarausziehung und Aussaugung finden kann. So sagt z. B. Arculanus (7)*): „Non omnis cataracta curatur per sectionem corneae, sed solum illa quae est immediata ipsi corneae et quae est fiuida. Et forte in hoc casu esset melius ut illud instrumentum esset perforatum ita ut cataracta posset sugi, et hoc instrumentum esset conveniens ad extrahendum saniem."

Uebrigens kann man sich auch aus dem Studium der neueren augenärztlichen Schriftsteller überzeugen, dass die Aussangung plastisch-seröser Ansammlungen der vorderen Kammer sich in directester Weise aus der in nicht genügender Weise vorgenommenen Hypopyonpunction - und die Hypopyonpunction oder was dasselbe sagen will die Staarausziehung wurde, wie wir dies im Lauf unserer Untersuchung auseinandergesetzt haben, von den Alten stets nur in einer solchen Weise ausgeführt, dass sie für alle dickflüssigeren und resistenteren Ergüsse durchaus unzureichend sein musste - entwickelt habe, also die Aussaugung nur eine Erweiterung oder Vervollständigung der Hypopyonpunction sei. So sagt z. B. Verdück (48)**): „Wenn der Eiter dick ist und kaum herauskommen kann, so kann unan ihn herausziehen, indem man ihn durch ein kleines Röhrchen heraussauget."

Wenn man also zur Zeit des Verdück, wo man doch in der Eröffnung der vorderen Kammer schon nicht mehr so zaghaft war und einen ausgiebigeren Schnitt in die Hornhaut bereits wagte, unter Umständen bei der Entfernung des Ergusses aus der vorderen Kammer in Verlegen-

*) Cap. XXX, p. 55 u. 56 .

*) Band I, Cap. XXI, p. 76 . 
heit gerieth und sich nicht anders als durch Aussaugen zu helfen wusste, um wie viel mehr und wie viel ofter werden die alten Operateure in derartige unbequeme Lagen gerathen sein, da bei der durch ihre physiologischen Vorstellungen gebotenen geringen Eröffnung der vorderen Kammer dickflüssigere Exsudate gewiss nicht durch die Eröffnung der Bulbuskapsel allein sich entfernen liessen. 


\section{Verzeichniss der von mir citirten Werke.}

1) Abynzoar. Theizir. Venetiis 1542.

2) Aelianus. De natura animalium. Herausgegeben von Friedrich Jacobs. Jena 1832.

3) Aetius. Libri universales quatuor. In: Medicae artis principes. Paris 1567.

4) Albucasis. De chirurgia. Arabice et latine. Ed. Channing. Oxonii 1778.

5) Ambroise Paré. Oeurres completes, revues et collationnées sur toutes les éditions par Malgaigne. Paris 1840.

6) Anagnostakis. Contributions à l'histoire de la chirurgie oculaire chez les Anciens. Athènes 1872.

7) Arculanus. In nonum Raxis ad regem Almansorem librum expositio. Venetiis 1558.

8) Averrois. Liber de medicina qui dicitur Colliget. Venetiis 1542.

9) Avicenna (Ibn Sina) Canon. Cum Gentilis Fulginatis comment. Venetiis 1492 .

10) Avicenna (Ibn Sina). Arabischer Text. Romae 1593.

11) Bartisch von Königsbräck. Augen-Dienst. Frankfurt 1584 und Sultzbach 1686.

12) Bernstein. Geschichte der Chirurgie. Leipzig 1822.

13) Brecht. Tobiae Leucomata. Dissert. Inaug. Tubingae 1743.

14) Bruni Longuburgensis Cyrurgia magna. Venetiis 1499.

15) Fritzsche. Kurzgefasstes exegetisches Handbuch zu den Apokryphen. Leipzig 1853.

16) Galeatii de sancta Sophia in nonum tractatum libri Rhasis ad regem Almansorem. Haganoae 1533.

17) Galenus. Opera omnia. Edit. curavit Kühn, Lipsiae 1825.

18) v. Graefe. Ueber v. Hasner's Kritik der Linearextraction. Separat-Abdruck aus: Klinische Monatsblätter für Augenheilkunde, 1868.

19) Gross. De operationibus ophthalmiatricis veterum. Inaug.Dissert. Berlin 1837.

20) Guilelmus de Saliceto. Summa conservationis et curationis. Venetiis 1489. 
21) Häser. Lehrbuch der Geschichte der Medicin. Erster Band. Jena 1875.

22) v. Haller. Elementa physiologiae corporis humani. Lausannae 1763. Tom. quintus.

23) Haly Filius $\Delta$ bbas. Liber de regali dispositione. A. Stephano ex arabica lingua in latinam satis ornatam reductus. Lugduni 1523.

24) v. Hasner. Dle neueste Phase der Staar-Operation. Prag 1868.

25) v. Hasner. Phakologische Studien. Eine Streitschrift über die Staaroperation. Prag 1868.

26) Hecker. Geschichte der Heilkunde. Berlin 1822.

27) Hirsch. Ein Wort zur Geschichte der Cataract-Extraction im Alterthum. Klinische Monatsblätter für Augenheilkunde. 1869.

28) Kühn. Index medicorum oculariorum inter Graecos Romanosque VII. Lipsiae 1830.

29) Lessing. Handbuch der Geschichte der Medicin. 1. Band. Berlin 1838.

30) Lewy. Ueber die Bedeutung des Antyllus, Philagrius und Posidonius. Janus 2. Band. Breslall 1847.

31) Marcellus. De medicamentis empiricis. Basileae 1536.

32) Oribasius Sardianus. Opera. In: Medicae artis principes. Paris 1567.

33) Paulus Aegineta. Opera. Joanne Andernaco interperete. Lugduni 1567.

34) Petri de Largelata Cirurgia. Venetiis 1513.

35) C. Plinii Secundi historia mundi. Ed. Dalecamp. Lugduni 1587 und Francofurti 1608.

36) C. Plinii Secundi Naturalis historia. Cam interpretatione et notis integris Joh. Harduini etc. Recensuit Franzius. Lipsiae 1781.

37) C. Plinii Secundi naturalis historia. Recensuit Sillig. Hamburgi et Gothae 1851.

38) Pollux. Onomasticon. Ed. Dindorf. Lipsiae 1824.

39) Rhases. Continens. Ordinatus et correctus per clarissimum artium et medicinae doctorem magistrum Hieronymum Surianum. Venetiis 1509 .

40) Rondeletius. Methodus curandorum omnium morborum corporis humani, in tres libros distincta. Francofurti 1592.

41) Rufus Ephesius. De appellationibus partium corporis humani. In: Medicae artis principes. Paris 1567.

42) Michaelis Savonarola. Practica major. Venetiis 1560.

43) Sichel. Historische Notiz über die Operation des grauen Staares durch die Methode des Aussangens oder der Aspiration. Archiv für Ophthalmologie. B. XIV, Abth. 3, Berlin 1868. 


\section{4}

44) K. Sprengel. Geschichte der Chirurgie. 1. Band. Geschichte der wichtigsten Operationen. Halle 1805.

45) Tischendorf. Vetus testamentum graece juxta LXX interpretes. Tomus primus. Lipsiae 1850 .

46) Trillerus, De scarificationis oculorum historia antiquitate et origine. Wittebergae 1754 .

47) Valescus de Tharanta. Philonium. Auroum ac perutile opus practicae medicinae. Venetiis 1521.

48) Joh. Baptista Verdück. Chirurgische Schriften. Aus dem Französischen übersetzt. Leipzig 1712.

49) Wallroth. Syntagma de ophthalmologia veterum. Halae 1818. 